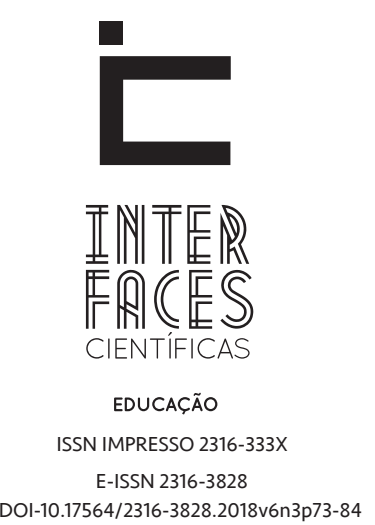

NÚMERO TEMÁTICO - PROCESSOS DE FORMACC̃O E ENSINO-APRENDIZAGEM NA CIBERCULTURA

\title{
DISPOSITIVOS TECNOLÓGICOS E AS TRANSFORMAÇ̃̃ES DAS PRÁTICAS DE APRENDIZAGEM DE JOVENS
}

TECHNOLOGICAL DEVICES AND THE TRANSFORMATION OF YOUTH LEARNING PRACTICES

DISPOSITIVOS TECNOLÓGICOS Y TRANSFORMACIONES DE LAS PRÁCTICAS DE APRENDIZAJE DE JÓVENES

Caio Mário Alcântara ${ }^{1}$

Marília Gabriele Melo $^{3}$
Luiz Rafael Santos Andrade 2

Ronaldo Linhares

\section{RESUMO}

0 artigo tem como objetivo fazer um estudo acerca das transformações das práticas de aprendizagem de jovens proporcionadas pelo uso de dispositivos tecnológicos enquanto recursos pedagógicos, tendo como base os estudos apresentados nos GT Educação e Comunicação no ANPED e Comunicação e Educação no Intercom durante os anos de 2004 e 2014. A pesquisa constrói reflexões que versam sobre as mediações culturais inseridas num contexto educacional pós-industrial, no qual as relações sociais se processam cada vez mais por intermédio de dispositivos da comunica- ção, como computadores, tablets e em especial, smartphones. Esse uso recorrente dos dispositivos tecnológicos tem produzido fenômenos antes desconhecidos e mostrado que o advento de novas ferramentas colabora com o desenvolvimento de novas habilidades culturais, em especial nos jovens estudantes.

\section{PALAVRAS-CHAVE}

Juventude. Tecnologia. Cultura. Aprendizado. 


\section{ABSTRACT}

The article aims to make a study about the transformation of youth's learning provided by the use of technological devices as pedagogical resources based on the studies presented in GT's Education and Communication in ANPED and Communication and Education in Intercom between the years of 2004 and 2014. The research builds reflections that deals with the cultural mediations inserted in a postindustrial educational context in which social relations are conducted increasingly through communication devices such as computers, tablets, and smartphones. This recurrent use of technological devices has produced phenomena previously unknown and shown that the advent of new tools contributes to the development of new cultural skills, especially in young students.

\section{KEYWORDS}

Youth. Technology. Culture. Learning.

\section{RESUMEN}

El artículo tiene como objetivo hacer un estudio sobre la transformación de las prácticas de aprendizaje de los jóvenes proporcionadas por el uso de dispositivos tecnológicos como recursos pedagógicos basados en los estudios presentados en GT Educación y Comunicación en ANPED y Comunicación y Educación en el Intercom para los años 2004 y 2014. La investigación se basa en reflexiones que tienen que ver con las mediaciones culturales insertadas en un contexto educativo posindustrial en que las relaciones sociales se llevan a cabo cada vez más a través de dispositivos de comunicación tales como ordenadores, tabletas, y, en particular, teléfonos inteligentes. Este uso recurrente de dispositivos tecnológicos ha producido fenómenos previamente desconocidos y que se muestran que el advenimiento de nuevas herramientas contribuye al desarrollo de nuevas habilidades culturales, especialmente entre los jóvenes estudiantes.

\section{PALABRAS CLAVE}

Juventud. Tecnología. Cultura. Aprendizaje. 


\section{INTRODUÇÃO}

A presença das tecnologias nos espaços de ação dos indivíduos caminha para um futuro de efetividade. Pessoas e dispositivos tecnológicos são elementos que tendem a se tornar indissociáveis nos espaços públicos e não se pode negar que essa relação de proximidade tem promovido uma sensação de fusão entre homem e máquina. Esse processo é mais evidente quando se faz um recorte de olhar. São os jovens os que fazem uso mais intenso de dispositivos móveis para efetuar uma enorme variedade de tarefas: desde o contato com amigos até pesquisas escolares e atividades profissionais.

Muitos desses jovens nasceram ou cresceram imersos em ambientes dominados por tecnologias. Alguns estudos buscam atestar o aprendizado mais eficaz com a mediação tecnológica, dentre os quais a pesquisa Teaching, learning and new technology: a review for teachers, realizado na Inglaterra (HARTLEY, 2007). Esse trabalho considerou dados colhidos entre 1985 e 2004 e comparou o aprendizado em diferentes contextos e níveis educacionais. Como resultado, foi percebido que ao contrário do que é especulado, os alunos que aprenderam a ler e escrever em dispositivos tecnológicos, desenvolveram essas habilidades com mais eficiência do que os estudantes de modelos tradicionais de ensino.

As tecnologias promovem certa liberdade em relação a padrões de escrita como formatação, caligrafia e edição do texto, além de pôr fim a problemas fisiológicos naturais do ato de escrever, dentre os quais a formação de calos nos dedos. Com isso os jovens ganham mais espaço para se concentrar nas argumentações e construção de ideias, acabando por escrever mais.

Esse pensamento pode até suscitar polêmicas, mas a afirmação é embasada em dados empíricos. Foram cruzadas informações colhidas com estudantes de 99 escolas inseridos na faixa etária entre 15 e 18 anos. 0 grupo que assistia a aulas em salas com recursos como lousa virtual apresentava melhor desempenho em fatores como leitura, tonicidade, separação silábica, pontuação e aumento de vocabulário.
Vale ressaltar que para o autor ainda não existe um consenso relativo aos benefícios da tecnologia no processo de alfabetização, mas, nas palavras dele, os alunos que "usam computadores na aprendizagem da escrita são mais engajados e motivados, produzindo textos mais longos e com mais qualidades" (HARTLEY, 2007, p. 49).

Essa relação jovem/mídia/aprendizado tem produzido material para investigações nos diferentes níveis e etapas educacionais. Ritchie et al (2013) investigou o uso dessas tecnologias por jovens estudantes da Universidade Autônoma da Baixa Califórnia, no México e chegou à conclusão de que esse grupo populacional tem de fato lançado mão de recursos tecnológicos como ferramenta de aprendizagem. Com o estudo ficou também comprovado que está havendo uma preferência pelo uso dos smartphones como recurso pedagógico em diferentes regiões do planeta. É preciso considerar que essa abordagem é mais comum em locais que possibilitam o contato dos estudantes com a tecnologia por meio do acesso à internet.

Nessa perspectiva de inserção dos dispositivos tecnológicos nos processos educacionais, o presente trabalho tem por objetivo a busca de um entendimento acerca dos efeitos promovidos pela utilização desses equipamentos enquanto ferramentas educacionais e para isso faz um estudo sobre as transformações das práticas culturais e de aprendizagem de jovens com base nos estudos apresentados nos GT Educação e Comunicação na ANPED e Comunicação e Educação no Intercom, os dois maiores e mais importantes eventos das áreas em questão, entre os anos de 2004 e 2014.

\section{REFLEXÕES SOBRE DISPOSITIVOS TECNOLÓGICOS DE APRENDIZAGEM}

Para que se inicie um estudo que leve em consideração as possibilidades de uso das tecnologias da informação e comunicação (TIC) nos espaços de ensino-aprendizagem, é preciso em primeira instância, conceituá-las. Para este trabalho entende-se que as 
TIC são dispositivos, que podem ser móveis - ressaltando nesses casos a característica de ubiquidade inerente a tablets e smartphones - ou fixos, como os computadores de mesa, em todos os casos, classificados como dispositivos.

No entendimento de Fischer (2002) os dispositivos são elementos inseridos nos processos de comunicação, ou seja, são plataformas que possibilitam a transmissão de produtos culturais, linguagens e estratégias de comunicação. Esse conceito está diretamente ligado ao pensamento Foucaultiano acerca dos conceitos de sujeito e de subjetividade. Foucault (1995) definiu o sujeito como todo e qualquer indivíduo que se encontra ligado ou subordinado a outro, quer seja por meio de relações culturais ou de poder. Já subjetivação é o processo pelo qual o homem passa a ser instruído, adequado a formatos e comportamentos inerentes a grupos sociais.

0 ponto de intersecção entre o pensamento de Fischer (2005) e o de Foucault (1995) reside nas estratégias utilizadas como forma de ensino nas escolas. 0 processo de aprendizado é em si uma prática de transmissão cultural. Neste parâmetro os alunos tornam-se sujeitos e quando os dispositivos tecnológicos passam a ser utilizados para estudar os fatos das ciências, que estão de forma direta ou indireta inseridos nos cotidianos sociais, contribuem para que os estudantes sejam transformados, concretizando 0 processo de subjetivação.

Nesta seara cabe a afirmação de que os dispositivos são recursos ou ferramentas que possibilitam aos estudantes e aos demais envolvidos nas etapas dos procedimentos pedagógicos, o contato com os conteúdos a serem estudados e aos elementos que possibilitam as discussões que vão culminar na concretização do aprendizado.

Vale ressaltar a existência de outros conceitos que apesar de serem norteados pelo pensamento de Foucault, distanciam-se em alguns aspectos. Uma abordagem relevante é a de que os dispositivos se constituem como ferramentas que possibilitam aos indivíduos acesso às produções culturais. É esse 0 conceito defendido ao se afirmar que "dispositivo é uma máquina abstrata, quase muda e cega, mas que faz ver e falar" (DELEUZE, 1998, p. 81). Uma contribuição presente nesta ideia é a de que o dispositivo é puramente uma ferramenta, um objeto que carrega em si significâncias direcionadas à valorização de elementos culturais.

Essa premissa é também defendida por Gaidulewiez (1999) ao caracterizar os dispositivos como plataformas tecnológicas disponíveis para a compreensão daqueles fenômenos sociais que são, por essência, complexos, heterogêneos e com elementos possuidores de mobilidade.

São essas características, ressaltando-se nesse caso o pensamento de que os dispositivos são ferramentas tecnológicas que transmitem conceitos e participam dos processos de aquisição de conhecimento cultural e aprendizagem, que fazem relações entre a existência dessas ferramentas e sua importância para a concretização das etapas pedagógicas.

\section{USO DE TECNOLOGIAS E A APRENDIZAGEM DE JOVENS}

A geração formada por meio da mediação dos dispositivos tecnológicos traz consigo uma série de práticas culturais que são desenvolvidas de maneira diferenciada em relação às gerações anteriores. Esses jovens estão nas escolas, fazendo uso de diversos dispositivos tecnológicos e aprendem a acessar sites, desbloquear aparelhos, fazer downloads praticamente sozinhos. Neste percurso aprimoram habilidades de leitura, compreensão e articulação de forma completamente autônoma, aprendizagem que está relacionada a uma pedagogia de compreensão do mundo.

Esse é um processo já explicado por Freire (2003) quando versa sobre o aprendizado do indivíduo a partir da relação das pessoas com os ambientes e elementos da vida cotidiana. Para ele "a leitura do mundo precede a leitura da palavra e a leitura desta implica a continuidade da leitura daquele" (FREIRE, 2003, p. 20).

Quando Freire (2003) escreveu sobre esse aprendizado a partir da análise de experiências da própria 
infância, ele sequer imaginava que um dia crianças e adolescentes teriam contato com equipamentos de tecnologia refinada, mas já antevia um processo que foi comprovado em 2003 em um trabalho realizado na Índia. Mintra (2003 apud HARTLEY, 2007) iniciou a série de experimentos que ficou conhecida como $A$ hole in the wall no qual sem serem dadas explicações, foram instalados um computador e um teclado na parede de uma escola.

0 pesquisador descreve que as crianças que estudavam no local começaram uma aproximação tímida com a máquina e em pouco tempo, mesmo sem um conhecimento prévio sobre informática, elas já criavam atalhos, acessavam programas e documentos e chegaram a criar termos específicos para nomear algumas tarefas e funções dos computadores. Em pouco tempo eles dominavam o uso de programas, faziam desenhos nos softwares e formaram grupos de poder para controlar o uso da máquina em horários específicos.

Neste sentido, Monteiro (2006) buscou uma compreensão sobre os impactos causados pelas tecnologias no âmbito da cultura dos jovens. Ao falar sobre o uso de celulares entre estudantes, o autor conceituou uma nova realidade dentro do ambiente escolar, que passou a ser dividido entre o grupo dos que tinham e dos que não tinham aparelhos. A partir dessa discussão ele comenta o quanto a importância dada às mídias configura a essência de fatos culturais - incluem-se aí os processos de aprendizagem - num movimento semelhante ao vivido pelas crianças na Índia.

Essa nova tecnologia aparece não mais apenas como um meio de comunicação entre as pessoas. Seus usos estão se tornando tão múltiplos que faz emergir uma mídia que fabrica novas culturas e faz (re)aparecer culturas que pareciam superadas. Seu uso no espaço escolar dialoga com as culturas e representações constitutivas de saberes que circulam, ainda, de forma hegemônica nas salas de aula, mas que também impõe novas regras, novas ações e novas alternativas metodológicas. (MONTEIRO, 2006, p. 8).

Essa relação de significância entre as tecnologias e o aprendizado de jovens foi também objeto de pesquisa para o estudo Los jóvenes en la era de la hiperconectividad: tendências, claves y miradas, realizado na Espanha e divulgado em 2013, no qual buscou-se uma compreensão acerca de alguns pontos inerentes ao uso das tecnologias comunicacionais - em especial as tecnologias móveis - enquanto ferramentas pedagógicas, levando em conta a forma como os jovens têm se relacionado com as mídias e a internet. De uma maneira geral foi percebido que nos últimos anos, e, principalmente, na última década, houve um crescimento considerável de jovens com acesso não apenas aos aparatos tecnológicos, como também à rede mundial de computadores. Esse índice saltou de 75,5\% em 2004 para 96,2\% em 2012.

O crescimento do uso desses recursos contribuiu para que o universo virtual ocupasse uma posição de cada vez mais relevância no cotidiano dos jovens, fazendo com que a preocupação acerca das implicâncias pedagógicas desse uso desenfreado viesse a se tornar primordial. Isso fica evidenciado quando Reig \& Vílchez (2013) expressam que

\begin{abstract}
El smartphone, las redes sociales o el WhatsApp, se han convertido en espacios vitales de los jóvenes y de los adolescentes desde edades cada vez más tempranas. Por ello existe una preocupación cada vez mayor por las implicaciones educativas de este proceso. La relación entre educación y TIC desborda hoy, en este nuevo contexto de hiperconectividad, los planteamientos más ligados al aprendizaje con tecnología, a la aplicación didáctica y pedagógica, y se adentra en campos más propios de la psicología social y de la psicología evolutiva. (REIG; VÍLCHEZ, 2013, p. 15).
\end{abstract}

Com a reflexão, os autores lembram que o que está havendo é uma transformação por meio da qual os processos educacionais estão tornando-se cada vez mais imersos em variados campos da vida pessoal, ou seja, com o avanço dos recursos tecnológicos que possibilitam conhecimento quase inesgotável e com acesso fácil e rápido, a ideia de uma educação que necessita de local e horário específico tem sido cada vez mais superada e com isso todos os ambientes passam a ter possibilidade de serem espaços pedagógicos. Hoje o jovem pode aprender na escola, em casa, no shopping ou no transporte a caminho de qualquer outra atividade. 
As modificações culturais, que, por conseguinte, podem ser consideradas como modificações nas estruturas e processos de aprendizagem dos jovens, são também levadas em consideração por Barbero (2002, p. 10), que defende o que ele chama de "revolução dos processos sociais". Essa alteração se consolida no início do século XXI, quando dois fenômenos surgem, promovendo modificações profundas nos relacionamentos sociais.

0 primeiro fator é a explosão das tecnologias da comunicação, que acabaram por influenciar até os formatos de produção e as relações parentais, além disso, houve um fortalecimento, Barbero chama de revitalização, das identidades. Grupos que antes viviam às margens das discussões econômicas e políticas passaram a ter representatividade nos ambientes virtuais, num movimento que trouxe à tona conflitos antes negligenciados, que vão desde o embate entre gerações até guerras.

Toda essa mudança é refletida nos ambientes pedagógicos, quer seja a sala de aula ou qualquer outro ambiente que pode ser utilizado para a finalidade pedagógica por conta da ubiquidade. Com as experiências descritas, torna-se claro que as mediações culturais existentes entre jovens dessa nova geração provocam mudanças consideráveis e dessa forma é imprescindível a busca pelo conhecimento produzido acerca desse fenômeno social.

\section{PRODUÇ̄̃O NOS GTS EDUCAÇ̃̃OE COMUNICAÇ̃̃O CANPED] E COMUNICAÇÃOE EDUCAÇÃO (INTERCOM)}

A partir das reflexões feitas sobre o uso de tecnologias nos espaços pedagógicos e a forma que esse uso vem sendo estudado e pensado em diferentes países, é importante levantar uma discussão sobre como o tema tem sido observado no Brasil. Para isso foram escolhidos os artigos apresentados entre os anos de 2004 e 2014 nos dois maiores eventos das áreas (educação e comunicação) realizados no país: o Intercom e o ANPED.
A Associação Nacional de Pós-Graduação e Pesquisa em Educação (ANPED) foi criada em 1976 e se constitui como um órgão que promove investigações científicas na área, sempre lutando pela universalização e desenvolvimento educacional brasileiro. Anualmente a instituição promove encontros nacionais, com periodicidade anual, nos quais diversos pesquisadores participam de conferências e apresentações de textos, divididos em $24 \mathrm{GT}^{2}$.

Já a Sociedade Brasileira de Estudos Interdisciplinares da Comunicação (INTERCOM) foi fundada em 1977 com o intuito de promover a troca de informações e conhecimentos entre pesquisadores e profissionais que atuam no mercado de trabalho. Hoje é a responsável pela organização de cinco congressos regionais, um colóquio binacional em parceria com instituições de países como Portugal, França, EUA, Canadá, Itália, México e Argentina e um congresso nacional realizado desde 1977, no qual também há apresentações de trabalhos em $29 \mathrm{GT}^{3}$.

Os dois eventos destinam grupos de trabalho para as discussões acerca da intersecção entre educação e comunicação - no caso do Intercom, o GT é denominado "Comunicação e Educação", já o ANPED designa o termo "Educação e Comunicação" - que tratam de temas como o uso de tecnologias como ferramentas

\footnotetext{
2 Os Grupos de Trabalho (GT) ANPED são os seguintes: História da Educação/ Movimentos sociais, Sujeitos e Processos Educativos/ Didática/ Estado e Política Educacional/ Educação Popular/ Educação de Crianças de 0 a 6 Anos/ Formação de Professores/ Trabalho e Educação/ Alfabetização, Leitura e Escrita/ Política da Educação Superior/ Currículo/ Educação Fundamental/ Sociologia da Educação/ Educação Especial/ Educação e Comunicação/ Filosofia da Educação/ Educação de Pessoas Jovens e Adultas/ Educação Matemática/ Psicologia da Educação/ Educação e Relações Étnico-raciais/ Educação ambiental/ Gênero, Sexualidade e Educação/ Educação e Arte.

3 Os Grupos de Trabalho (GT) do Intercom são: Gêneros Jornalísticos/ História do Jornalismo/ Jornalismo Impresso/ Teoria do Jornalismo/ Telejornalismo/Publicidade e Propaganda/Comunicação Organizacional/ Cinema/ Ficção Seriada/ Fotografia/ Rádio e Mídia Sonora/ Televisão e Vídeo/ Cibercultura/ Conteúdos Digitais e Convergências Tecnológicas/ Comunicação e Culturas Urbanas/ Comunicação e Educação/ Comunicação e Esporte/ Comunicação, Ciência, Meio Ambiente e Sociedade/ Comunicação, Música e Entretenimento/ Produção Editorial/ Comunicação e Desenvolvimento Regional e Local/ Comunicação para a Cidadania/ Geografias da Comunicação/ Mídia, Cultura e Tecnologias Digitais na América Latina/ Comunicação, Mídias e Liberdade de Expressão/ Políticas e Estratégias de Comunicação/ Folkcomunicação/ Semiótica da Comunicação/ Teorias da Comunicação.
} 
de aprendizagem, educação a distância, formação de professores, metodologias de ensino online e receptividade de mídias.

Para que se construam reflexões relacionadas ao objetivo principal do presente trabalho, a saber, construir um estudo acerca das transformações das práticas culturais e de aprendizagem de jovens proporcionadas pelo uso de dispositivos tecnológicos enquanto recursos pedagógicos, foi escolhido analisar todo o material publicado nos GT já citados, que fazem análises ligadas ao uso dessas tecnologias enquanto ferramentas de aprendizagem e o possível impacto nas transformações culturais que essa prática pode ocasionar.

A busca foi realizada nos sites das duas instituições nos quais estão disponibilizados os anais dos eventos. Após acessar esses arquivos, foi digitado nas plataformas de buscas os seguintes termos específicos: tecnologia; jovens; aprendizado; cultura; mídia; receptividade; comunicação; educação; mediação e escola. Com esses indexadores foram encontrados 64 artigos (30 nos anais do Intercom e 34 nos anais do ANPED). 0 primeiro aspecto analisado foi o resumo de cada um (para saber quais as temáticas trabalhadas), os objetivos e a quais conclusões chegaram. Esses dados serviram de material para uma tabulação construída com os resultados obtidos, a partir da qual foi possível perceber novos fatores, dentre os quais a preferência dos pesquisadores pelo trabalho empírico.

Do total de artigos pesquisados mais de $79 \%$ eram análises de pesquisas realizadas em campo, quer seja em escolas (sempre da rede pública) de ensino infantil, fundamental e médio, ou em nível universitário. Apenas 13 trabalhos - menos de $21 \%$ do total - dedicaram-se a discussões exclusivamente epistemológicas.

Mas a natureza dos trabalhos não foi a única característica observada. Em relação ao conteúdo também foi possível a percepção de um fator considerado importante para a compreensão da forma como os pesquisadores têm estudado o uso de tecnologias enquanto ferramentas pedagógicas e esse fator está relacionado aos objetos de estudo. Ao contrário do que era esperado, ao invés dos estudos serem centrados nos jovens estudantes, o foco maior é dado aos pro- fessores e às transformações culturais advindas dos recursos tecnológicos. Esse fato foi percebido tanto nos artigos publicados nos anais do Intercom, assim como nos anais do ANPED. Isso pode ser observado nos gráficos seguintes.

Tabela 1 - Objetos de estudo ANPED

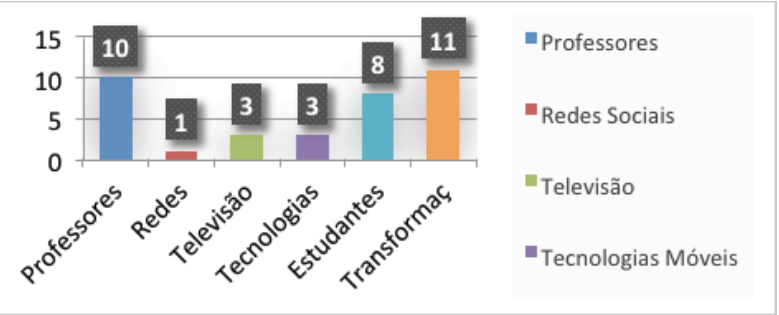

Fonte: Dados da pesquisa.

Tabela 2 - Objetos de estudo Intercom

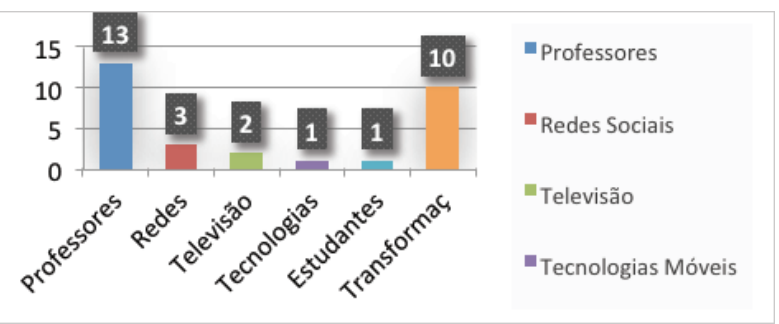

Fonte: Dados da pesquisa.

Foi possível perceber que à medida que os anos foram avançando, as tecnologias que eram analisadas nos trabalhos também sofreram modificações. No geral, tanto os trabalhos apresentados no Intercom, como os publicados pelo ANPED, fizeram reflexões baseadas na inserção da televisão na sala de aula entre os anos de 2005 e 2008, ressaltando que no ano de 2004 foram encontrados dois textos, contudo os dois não estavam disponíveis para download. Entre 2009 e 2011, os textos voltaram a atenção para os ambientes virtuais de aprendizagem, para programas de governo, como o Programa Um Computador Por Aluno (PROUCA) e começaram a surgir algumas abordagens acerca do uso de tecnologias móveis. Foi somente a partir de 2012, que as ferramentas que promovem a 
ubiquidade e as redes sociais passaram a ser inseridas entre os principais objetos de pesquisa.

Além desses registros, houve incidência de trabalhos que abordaram outros temas. Dois artigos fizeram análises de meios de comunicação e como eles colaboram para a construção do discurso científico, um discorreu sobre letramento digital e capacitação de agentes de saúde, um trabalho fez uma revisão dos artigos publicados nos GT Educação e Comunicação (ANPED) e Comunicação e Educação (INTERCOM) no ano de 2010 e apenas um trabalho usou os mesmos indicadores analisados pela presente pesquisa (jovens; aprendizado; cultura; mídia; receptividade; comunicação; educação; mediação e escola) para buscar uma reflexão acerca das contribuições do cinema para o aprendizado.

Com a leitura dos textos e análise dos dados obtidos é possível a construção de alguns entendimentos acerca da forma como os dispositivos tecnológicos têm sido compreendidos por pesquisadores brasileiros sob o aspecto do uso dessas tecnologias enquanto recurso de aprendizagem. De início percebe-se que quase a totalidade dos autores considera que de fato há uma contribuição relevante por parte das mídias, que podem ser aliados de estudantes e de professores para contribuir com o percurso pedagógico.

Uma das defensoras desse princípio é Fantin (2011) que credita às mídias a possibilidade de estimular habilidades relacionadas à leitura - tanto da palavra como de mundo - quando se considera que elas possuem linguagens, textualidades e dimensões discursivas que quando utilizadas tanto de forma autônoma, como também orientada, colaboram com o desenvolvimento dos estudantes. É um conceito também defendido por Girardelo (2011) que analisou o desempenho de crianças da cidade de Nova lorque (EUA) na construção de narrativas em plataformas digitais. Na pesquisa desenvolvida pelo autor é pontuado que a atividade mostrou que as narrativas criadas pelos estudantes a partir dos dispositivos tecnológicas contribuíram de forma efetiva com o processo de alfabetização e letramento.

No âmbito do desenvolvimento de habilidades mediado por tecnologias, Citelli (2012) lembra que esses dispositivos tecnológicos já se configuram como um elemento comum à vida de jovens, provocando mudanças profundas e que precisam ser consideradas no momento de aprendizagem. Ele defende que o processo de letramento está, ao se pensar sobre as novas gerações, ligados à compreensão dos usos possíveis das ferramentas tecnológicas.

A questão relativa ao uso de tecnologias nos ambientes pedagógicos não tem sido debatida apenas no âmbito do desenvolvimento de habilidades. Ferreira \& Linhares (2012) comentam que a resistência da instituição escolar em promover a utilização das tecnologias da comunicação consiste no que eles chamam de "miopia sobre a diversidade das realidades socioculturais e dos novos espaços de aprendizagem possibilitados pelas tecnologias" (FERREIRA; LINHARES, 2012, p. 2).

Esses novos espaços suscitaram o interesse de Souza (2013), pesquisador do fenômeno dos percursos de aprendizagem promovidos pelas redes sociais. Em seu estudo, ele busca compreender quão o Facebook tem sido utilizado como plataforma para aquisição de conhecimentos por parte de estudantes, em especial os universitários. 0 quadro revelado é de que a tecnologia já se constitui como uma realidade inerente ao cotidiano dos estudantes de ensino superior dos centros urbanos. No caso específico, $71 \%$ dos entrevistados pelo autor afirmaram que vivem constantemente conectados, em especial nas redes sociais e dentre eles, 91\% dizem que não contentam-se em ler as postagens, mas buscam ser autores e fazer comentários.

Em relação aos professores o que foi apreendido com base nas pesquisas apresentadas nos dois eventos é que falta qualificação em todos os níveis possíveis, ou seja, o déficit de especialização é perceptível na formação continuada, mas é ainda mais grave quando se pensa a formação inicial do profissional. É o que apregoa Gonçalves (2006) afirmando que “formar professores tem se constituído desafio sem precedentes e o modelo de formação construído historicamente mostrou-se insuficiente para dar conta da compreensão dos problemas concretos da prática pedagógica” (GONÇALVES, 2006, p. 4). 
A mesma linha de pensamento é defendida por Pereira (2008), que analisou o uso de tecnologias em uma escola de ensino fundamental da cidade de Florianópolis. Para o autor "não parece estar havendo formação suficiente ou adequada das professoras que promova ou estimule usos críticos e criativos [das mídias]" (PEREIRA, 2008, p. 14).

Também houve o registro de trabalhos que fazem o alerta para os cuidados necessários relativos ao uso dos dispositivos, principalmente no que tange a necessidade de readequação dos padrões escolares. Para alguns autores chegou o momento em que as mudanças culturais são tão presentes e marcantes que as propostas pedagógicas, mesmo as mais modernas, têm se apresentado como insuficientes para prover formação aos estudantes, em especial ao se considerar que há um déficit entre a linguagem dessas novas gerações e o discurso pedagógico, que tem encontrado barreiras para o entendimento até entre os professores recém-formados (CITELLI, 2013, p. 13).

Com o exposto torna-se possível a compreensão de que o choque entre o modelo educacional vigente e as novas gerações de alunos que têm adentrado na escola é cada vez mais evidente. Esses estudantes desenvolvem com facilidade novas habilidades culturais - sempre de forma autônoma - e a escola precisa assimilar essa realidade, assumindo o papel que the cabe de mediação e principalmente orientação.

\section{CONCLUSÕES}

Para que se chegue a uma conclusão, ou ao menos um entendimento prévio, acerca do papel que as mídias e dispositivos tecnológicos desempenham enquanto atores das transformações de práticas culturais e de aprendizagem de jovens é preciso compreender que esse quadro de mudanças nas abordagens sociais é um fenômeno que caminha a passos largos e acelerados para se tornar realidade geral. Os jovens mantêm acesso constante ao ciberespaço, principalmente por meio das tecnologias móveis e ubíquas.

Em vista disso pode-se afirmar que o letramento de crianças e jovens se tornou um processo autônomo completamente imerso na hipertextualidade e, portanto, para que a escola continue desempenhando sua função primeira de tutelar o acesso ao conhecimento ela precisa construir uma reformulação profunda, que não se constitua em meros atos paliativos, geralmente estimulados por motivação pessoal e esporádica de professores.

Neste sentido é importante ressaltar a contribuição que a internet e dispositivos como smartphones, elementos já constantes na vida dos jovens, agregam ao desenvolvimento pessoal e, por conseguinte, cultural das gerações pós-contemporâneas e que deve ser alvo de políticas de estado e de formação inicial de pedagogos e professores, profissionais que sempre foram e precisam continuar sendo as peças mais fundamentais no ensino-aprendizagem.

Os trabalhos publicados nos eventos e discutidos aqui mostram que de fato há uma mudança no modo ser e de aprender dos jovens. Essa transformação está diretamente relacionada ao avanço das TIC e configura a relevância que esses equipamentos têm nos processos de subjetivação. 0 estudo também possibilitou a verificar que os objetos de estudo foram se modificando ao longo de uma década, acompanhando a disponibilidade de equipamentos e tecnologias.

\section{REFERÊNCIAS}

BARBERO, J.M. Dos meios às mediações: comunicação, cultura e hegemonia. 4.ed. Rio de Janeiro: UFRJ, 2006.

BARBERO, J.M. Jóvenes: comunicación e identidade. Pensar Iberoamérica revista de cultura, fev. 2002.

BARBERO, J.M. Tecnicidades, identidades, alteridades: desubicaciones y opacidades de la comunicación em el nuevo siglo. Diálogos da Comunicação. Peru, 2002.

BLAIR, B.L. et al. Cell Phone Decision Making: Adolescents' Perceptions of How and Why They 
Make the Choice to Text or Call. Youth and Society, Thousands Oaks, n.1, p.1-17, 2013

BOTTENTUIT JÚNIOR, J.B.; COUTO, F.A. O uso das tecnologias de informação e comunicação no Ensino Fundamental II: um estudo com alunos e professores de uma escola em São Luís - MA. Revista Educaonline, Rio de Janeiro, v.6, n.2, p.51-93, 2012.

DELIUZE, G. Foucault. São Paulo: Brasiliense, 1998.

\section{FERREIRA, H.M.C. Dinâmicas de uma juventude}

conectada: a mediação dos dispositivos móveis nos processos de aprender-ensinar. 2014. 270f. Tese (Doutorado em Educação) - Programa de PósGraduação em Educação, Universidade do Estado do Rio de Janeiro, Rio de Janeiro, 2014.

FREIRE, P. A importância do ato de ler: em três artigos que se complementam. São Paulo: Cortez, 2003.

FREIRE, P. Pedagogia da autonomia. São Paulo: Paz e Terra, 2011.

FISCHER, R.M.B. O dispositivo pedagógico da mídia: modos de educar na (e pela) TV. Educação e Pesquisa, São Paulo, v.28, n.1, p.151-162, jan-jun. 2002.

FOUCAULT, M. O sujeito e o poder. In: DREYFUSS, H.; RABINOW, P. Uma trajetória filosófica: para além do estruturalismo e da hermenêutica. Rio de Janeiro: Forense, 1995.

GAIDULEWIEZ, L. El concepto de dispositivo en el pensamiento de Foucault. In.: SOUTO, M. et al. Grupos y dispositivos de formación. Buenos Aires: Universidad de Buenos Aires, 1999.

HARTLEY, J. Teaching, learning and new technology: a review for teachers. British Journal of

Educational Technology, Oxford, v.38, n.1, p.4262, 2007.

LEVY, P. O que é o virtual? São Paulo: 34, 1996.

LEVY, P. Cibercultura. São Paulo: 34, 1996.

PORTO, C.; SANTOS, E. Facebook e educação:

publicar, curtir, compartilhar. João Pessoa: Eduepb. 2014.

REIG, D.; VÍLCHEZ, L.F. Los jóvenes en la era de la hiperconvectividad: tendências, claves y miradas. Madrid: Fundación Telefónica. 2013.

\section{SANTAELLA, L. Potenciais desafios da} sociedade informacional. Conferência magistral no $9^{\circ}$ Congresso Mundial de Informação em Saúde e Bibliotecas. Salvador-BA, de 20 a 23 de setembro de 2005. 


\begin{abstract}
1 Doutorando em Educação pela Universidade de Aveiro; Mestre em Educação pelo Programa de Pós-Graduação em Educação da Universidade Tiradentes; Graduado em Comunicação Social - Jornalismo, tem experiência na área de telejornalismo, assessoria de comunicação e edição de texto; Membro do grupo de pesquisa Educação, Comunicação e Sociedade (GECES/CNPq) no qual desenvolve pesquisas nas áreas de educação e tecnologias, formação de professores e avaliação, em especial avaliação como aprendizagem; Integrou a equipe do projeto de extensão Unit Notícias, telejornal laboratório do curso de Jornalismo da Universidade Tiradentes; Foi por dois anos, membro da equipe de jornalismo da TV Aperipê, onde desempenhou as funções de repórter, apresentador e editor de texto; Participou da oficina de Comunicação e Mídia, desenvolvida pelo Instituto Luciano Barreto Júnior, como educador social; Atualmente é Full Member da Honor Society Organization. E-mail: caiogmalcantara@gmail.com
\end{abstract}

2 Doutorando em Educação, Mestre em Educação com bolsa na modalidade CAPES/FAPITEC e Graduado em Licenciatura Plena em História pela Universidade Tiradentes - UNIT; Pesquisador vinculado ao Grupo de Estudos e Pesquisa Comunicação, Educação e Sociedade - GECES/ CNPq; Realiza pesquisa em Educação, com ênfase em Alfabetização Informacional e Letramento Digital: E-mail: andrade.luizrafael@gmail.com

3 Mestre em Educação, com ênfase em Educação e Comunicação, pela Universidade Tiradentes - UNIT; Pós-graduada em Comunicação, Marketing e Assessoria de Imprensa pela Faculdade Pio Décimo; Graduada em Comunicação Social - Jornalismo e em Letras Português pela Universidade Tiradentes - UNIT; Membro do Grupo de Pesquisa Comunicação, educação e sociedade - GECES. E-mail: gabi_1785@hotmail.com

4 Graduado Licenciatura e Bacharelado em História (1986) e Mestre em Educação (1996) pela Universidade Federal de Sergipe - UFS; Doutor em Ciências da Comunicação (2003) pela Universidade de São Paulo - USP; Professor Titular do Programa de Pós Graduação em educação da Universidade Tiradentes - UNIY; Professor - Secretaria de Educação do Estado de Sergipe; avaliador do Instituto Nacional de Estudos e Pesquisas Educacionais Anísio Teixeira; Pesquisador do Instituto de Tecnologia e Pesquisa; Membro de comitê cientifico da Fundação de Apoio à pesquisa e à Inovação Tecnológica do estado de Sergipe, avaliador ad hoc da Fundação de Apoio a pesquisa e a Inovação Tecnológica do Estado de Sergipe; Tem experiência na área de Educação, com ênfase em Tecnologia Educacional, atuando principalmente nos seguintes temas: educação, educação a distância, formação de professores, formação de professor e avaliação: Coordena o Grupo de Pesquisa Comunicação, Educação e Sociedade CAPES/UNIT; Coordena o Simpósio Internacional Educação e Comunicação. E-mail: ronaldo_linhares@unit.br 
